\title{
Hydrogen sulfide regulates bone remodeling and promotes orthodontic tooth movement
}

\author{
HAIYA PU and YONGMEI HUA \\ Department of Orthodontics, School of Dentistry, Tongji University, Shanghai Engineering \\ Research Center of Tooth Restoration and Regeneration, Shanghai 200233, P.R. China
}

Received March 22, 2017; Accepted September 1, 2017

DOI: $10.3892 / \mathrm{mmr} .2017 .7813$

\begin{abstract}
Hydrogen sulfide $\left(\mathrm{H}_{2} \mathrm{~S}\right)$ is a gas signaling molecule that has multiple influences on physiological and pathological processes in the mammalian body, including vasodilation, neurotransmission, inflammation, hypoxia sensing and bone remodeling. Our previous studies suggested that $\mathrm{H}_{2} \mathrm{~S}$ might be involved in the periodontal tissue remodeling during the orthodontic tooth movement (OTM) via increasing periodontal ligament cell differentiation, tissue mineralization, bone formation and collagen synthesis. The aim of the present study was to investigate the effects of $\mathrm{H}_{2} \mathrm{~S}$ on alveolar bone remodeling that is associated with tooth movement. Experiments were performed in an OTM mouse model. Sodium hydrosulfide (NaHS), which is a donor of $\mathrm{H}_{2} \mathrm{~S}$ and DL-propargylglycine (PAG) and a cystathionine- $\gamma$-lyase (CSE) inhibitor, which could also decrease $\mathrm{H}_{2} \mathrm{~S}$ expression, were administered intraperitoneally and respectively. A total of 60 male C57BL6/J mice were divided into 4 groups; Control, NaHS, PAG and combination (PAG+NaHS). The rate of OTM and the bone mineral density (BMD) of alveolar bone were scanned and measured by micro-computed tomography (micro-CT). The number of osteoclasts and expression of the tumor necrosis factor ligand superfamily member-11 (RANKL), alkaline phosphatase (ALP), osteocalcin (OCN) and osteoprotegerin (OPG) in alveolar bone were accessed to evaluate the osteoclastic activity and osteogenesis with histochemistry of tartrate-resistant acid phosphatase staining, immunohistochemistry and reverse transcription-quantitative polymerase chain reaction. In the alveolar bone, NaHS increased the OTM and decreased the BMD, respectively. PAG significantly decrease OTM and increased the BMD. NaHS combined with PAG rescued the PAG-induced changes in the OTM and the
\end{abstract}

Correspondence to: Professor Yongmei Hua, Department of Orthodontics, School of Dentistry, Tongji University, Shanghai Engineering Research Center of Tooth Restoration and Regeneration, 399 Middle Yan Chang Road, Shanghai 200233, P.R. China E-mail: yongmeihua@tongji.edu.cn

Key words: hydrogen sulfide, bone remodeling, orthodontic tooth movement, mouse model
BMD. Additionally, the number of osteoclasts, the expression of RANKL, ALP, OCN and the ratio of RANKL/OPG were significantly up-regulated in the NaHS group. In contrast, PAG down-regulated the number of osteoclasts, the expression of RANKL, ALP, OCN and the ratio of RANKL/OPG. These findings suggested that $\mathrm{H}_{2} \mathrm{~S}$ might facilitate the OTM by enhancing alveolar bone remodeling as a result of an increased osteoclastic activity and osteogenesis.

\section{Introduction}

In the process of orthodontics treatment, mechanical force is loaded on the tooth, resulting in the production of inflammatory mediators in periodontal tissues, and the surrounding alveolar bone is remodeled. According to the pressure-tension theory (1), bone resorption occurs on the side of root under pressure, while bone formation occurs on the other side of the root under tension. The bone remodeling in the dental and periodontal tissues enables the tooth to move in the alveolar bone $(2,3)$. A previous study demonstrated alternations of the alveolar bone density due to active bone remodeling during orthodontic treatment, the reduction of alveolar bone density results from less bone mineral content as a result of resorption of pre-existing bone tissue and formation of new bone tissue during the process of bone remodeling (4). Therefore, it is likely that bone mineral density (BMD) reflects progress of bone remodeling during orthodontic treatment. Additionally, some cell factors and proteins including tumor necrosis factor ligand superfamily member-11 (RANKL), osteoprotegerin (OPG), lubricin and tumor necrosis factor-related apoptosis-inducing ligand were also proved to influence the bone remodeling in orthodontic tooth movement (OTM) (5-7).

Hydrogen sulfide $\left(\mathrm{H}_{2} \mathrm{~S}\right)$ can be produced by at least three enzymes: Cystathionine $\beta$-synthetase (CBS), cystathionine $\gamma$-lyase (CSE) and 3-mercaptopyruvate sulfurtransferase in mammals $(8,9)$. As a gasotransmitter, $\mathrm{H}_{2} \mathrm{~S}$ serves a vital role in various physiological and pathophysiological processes, including vasodilation, neurotransmission, inflammation, antiinflammation and hypoxia sensing (10-14). In rat periodontal tissues, $\mathrm{H}_{2} \mathrm{~S}$ increases the osteoclast activity and upregulates RANKL expression levels $(15,16)$. It was reported that human periodontal ligament stem cells (PDLSCs), expressed both CBS and CSE and produced $\mathrm{H}_{2} \mathrm{~S}$, which maintained the osteogenic capacity of PDLSCs (17). Our previous study 
indicated that human PDLSCs produced $\mathrm{H}_{2} \mathrm{~S}$ via CSE, and the mechanical stimuli increased the mRNA expression levels of CSE. Another study suggested that mechanical stimuli promoted the production of $\mathrm{H}_{2} \mathrm{~S}$ in human PDLSCs (18). In has also been demonstrated that $\mathrm{H}_{2} \mathrm{~S}$ could promote osteogenic differentiation of human PDLSCs by activating the p38-mitogen-activated protein kinase and the extracellular signal-regulated kinase signaling pathways (19).

However, the effect of $\mathrm{H}_{2} \mathrm{~S}$ on alveolar bone remodeling has not been extensively investigated, as most studies are based on in vitro investigation without in vivo evidence. The aim of this study was to explore the effects of $\mathrm{H}_{2} \mathrm{~S}$ on alveolar bone formation and resorption in an OTM mouse model. Results of this study may provide an understanding on $\mathrm{H}_{2} \mathrm{~S}$ mechanisms of action on orthodontic tooth movement and a potential approach to accelerate orthodontic treatment.

\section{Materials and methods}

Animals. A total of 60 8-week old male C57BL6/J mice were used in this study in accordance with a protocol approved by the Animal Use and Care Committee of Tongji University (Shanghai, China). This study was granted ethical approval by Medical Ethics Committee of Tongji University, Shanghai, China. Mice were housed under specific pathogen-free conditions with a controlled temperature $\left(22 \pm 1^{\circ} \mathrm{C}\right)$, humidity (40-60\%) and a 12-h light/dark cycle. The animals were given soft diet and water, ad libitum. The general condition and weight of each animal in this study were monitored during all experiments. In the present study, mice were divided into four groups, including a control $(\mathrm{n}=15)$, a sodium hydrosulfide (NaHS; $n=15)$, a DL-propargylglycine (PAG; $n=15)$ and a combination group (PAG+NaHS; $n=15)$. Both NaHS $\left(\mathrm{a}_{2} \mathrm{~S}\right.$ donor, Sigma-Aldrich; Merck KGaA, Darmstadt, Germany) and PAG (a CSE inhibitor, Sigma-Aldrich; Merck KGaA) were administered intraperitoneally at a dose of $10 \mathrm{mg} / \mathrm{kg} / \mathrm{day}$ for 14 days, and a micro-computed tomography (micro-CT) scan was performed on day 14. Following the sacrifice of mice with an overdose of anesthetic (10\% chloralic hydras, $400 \mathrm{mg} / \mathrm{kg}$, Sigma-Aldrich; Merck KGaA), tissues were collected for further histological, immunohistochemical and molecular biology analyses. Briefly, tissues were fixed in $4 \%$ paraformaldehyde at $4^{\circ} \mathrm{C}$ for $24 \mathrm{~h}$, followed by incubation with $10 \%$ ethylenediaminetetraacetic Acid ( $\mathrm{pH}$ 7.4) for decalcification $\left(4^{\circ} \mathrm{C}\right.$ for 4 weeks). Sections ( $5 \mu \mathrm{m}$ thick) were cut by a microtome (Leica RM2235, Leica Microsystems Ltd., Wetzlar, Germany) in a mesiodistal direction parallel to the long axis of mesial root of the first molar. Sections that included mesial roots and the alveolar bone of the first molar were selected for titrate-resistant acid phosphatase (TRAP) and immunohistochemical staining.

Establishment of the OTM model. An OTM mouse model was set up as described in a previous study (20). Orthodontic force was generated by a nickel-titanium coiled spring $(0.2 \mathrm{~mm}$ in thickness, $1 \mathrm{~mm}$ in diameter and $1 \mathrm{~mm}$ in length, Smart Technology Co, Ltd., Beijing, China) bonded between the maxillary right first molar and the incisors with flowable restorative resin (3M ESPE, St. Paul, MN, USA), producing $\sim 35 \mathrm{~g}$ force (21) (Fig. 1). A dynamometer (YDM Corporation,
Table I. Primer sequences of $A L P, O C S, O P G, R N K L$ and GAPDH.

\begin{tabular}{llc}
\hline Gene & \multicolumn{1}{c}{ Primer Sequence (5'-3') } & $\begin{array}{c}\text { Length } \\
\text { (bp) }\end{array}$ \\
\hline ALP & F: ACACTCGGCCGATCGGGACT & 20 \\
& R: CCGCCACCCATGATCACGTCG & 21 \\
OCN & F: TAGTGAACAGACTCCGGCGCTA & 22 \\
& R: TGTAGGCGGTCTTCAAGCCAT & 21 \\
OPG & F: GTGGAATAGATGTCACCCTGTGT & 23 \\
& R: TTTGGTCCCAGGCAAACTGT & 20 \\
\multirow{2}{*}{ RANKL } & F: CAGAAGATGGCACTCACTGCA & 21 \\
& R: CACCATCGCTTTCTCTGCTCT & 21 \\
GAPDH & F:AGCAGTCCCGTACACTGGCAAAC & 23 \\
& R:TCTGTGGTGATGTAAATGTCCTCT & 24 \\
\hline
\end{tabular}

F, forward; R, reverse; ALP, alkaline phosphatase; OCN, osteocalcin; OPG, osteoprotegerin; RANKL, tumor necrosis factor ligand superfamily member- 11 .

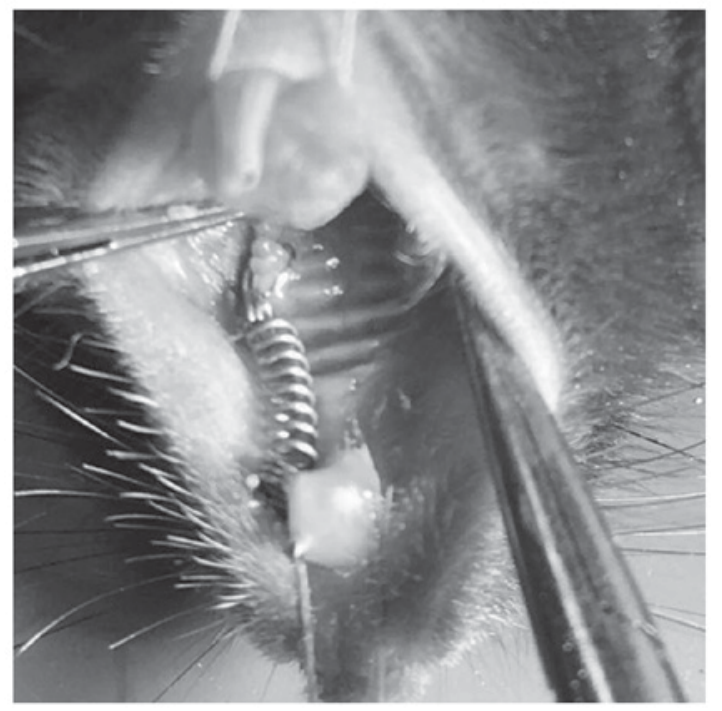

Figure 1. Representative image of the orthodontic appliance in an OTM mouse model

Tokyo, Japan) was used to measure the force accurately. The distance between the first and the second molar in mice was identified as OTM.

Micro-CT scanning. Microarchitecture of the maxillary was scanned and the distance between the maxillary first and the second molar was measured using micro-CT (SCANCO Medical AG, Bruttisellen, Switzerland). The BMD of alveolar bone in the root furcation area was analyzed quantitatively by a self-contained 3D analysis software of micro-CT (SCANCO Medical AG, Bruttisellen, Switzerland), by assessing the bone volume over total volume (BV/TV).

TRAP immunohistochemistry. TRAP staining $\left(37^{\circ} \mathrm{C}, 1 \mathrm{~h}\right)$ was performed to identify and quantify osteoclasts using a TRAP 
A

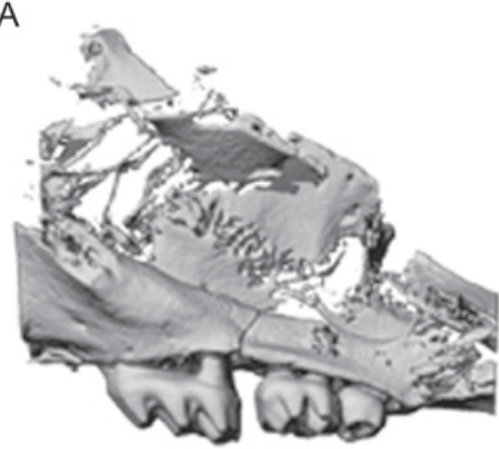

$-100 \mu \mathrm{m}$

C

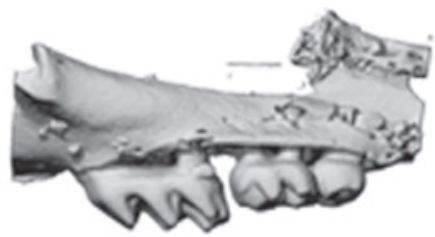

$-100 \mu \mathrm{m}$

E

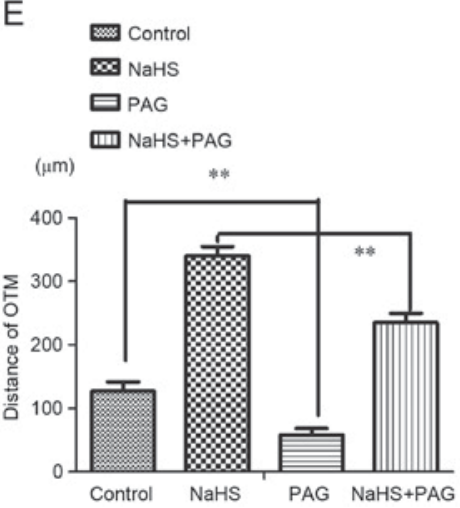

B

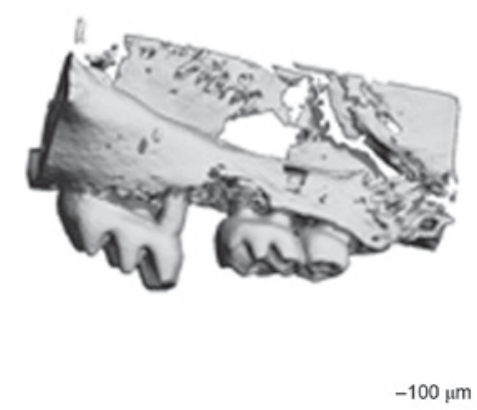

D

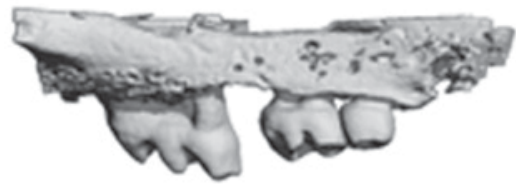

$-100 \mu \mathrm{m}$

Figure 2. Micro-computed tomography images of interdental distance between first and second molar teeth of the (A) control, (B) NaHS, (C) PAG and (D) $\mathrm{PAG}+\mathrm{NaHS}$ groups, and (E) quantification of the changes in the molar tooth movement. Data are presented as the mean \pm standard deviation. ${ }^{* *} \mathrm{P}<0.01$. OTM, orthodontic tooth movement; NaHS, sodium hydrosulfide; PAG, propargylglycine.

ELISA kit (cat. no. 387A, Sigma-Aldrich; Merck KGaA) according to the manufacturer's protocol. The osteoclasts of the alveolar bone located between the first and second molar were counted under a confocal microscope (NIKON ECLIPSE $80 \mathrm{i}$, Nikon Corporation, Tokyo, Japan).

RNA extraction and reverse transcription polymerase chain reaction ( $R T-q P C R)$. Total RNA was extracted from the alveolar bone surrounding the upper region of the first molar using TRIzol reagent (Sigma-Aldrich; Merck KGaA). A RT-qPCR Kit (Takara Bio, Inc., Otsu, Japan) was used to reverse transcribe the RNA to complementary (c)DNA, according to the manufacturer's protocol, the conditions of reactions were: $30^{\circ} \mathrm{C}$ for $10 \mathrm{~min}, 42^{\circ} \mathrm{C}$ for $30 \mathrm{~min}, 99^{\circ} \mathrm{C}$ for $5 \mathrm{~min}$ and $4^{\circ} \mathrm{C}$ for $5 \mathrm{~min}$. Relative mRNA levels of alkaline phosphatase $(A L P)$, osteocalcin $(O C N), O P G$ and $R A N K L$ were determined using a SYBR Green PCR Master mix and an ABI 7500 Real-Time PCR Detection System (Roche Diagnostics, Basel, Switzerland). Primer sequences are listed in Table I. The conditions of reactions were: Initial denaturation at $94^{\circ} \mathrm{C}$ for $3 \mathrm{~min}$ and followed by 35 cycles of denaturation at $95^{\circ} \mathrm{C}$ for $10 \mathrm{sec}$, and annealing at $57^{\circ} \mathrm{C}$ for $30 \mathrm{sec}$. Reactions were run in triplicate and mean-averaged the results. Relative fold changes were calculated using the method of $2^{-\Delta \Delta C q}(22)$. GAPDH was used as the housekeeping gene.

Immunohistochemistry. Following routine deparaffinage with $100 \%$ xylene for $20 \mathrm{~min}$ at room temperature, and hydration with alcohol gradient, $3 \% \mathrm{H}_{2} \mathrm{O}_{2}$ was used to inactivate endogenous enzymes for $30 \mathrm{~min}$ at room temperature. Antigen repair was performed with Trypsin (Sigma-Aldrich; Merck KGaA) for $20 \mathrm{~min}$ at room temperature. Sections were incubated with primary antibodies (ALP, cat. no. SAB3700030; OCN, cat. 
A

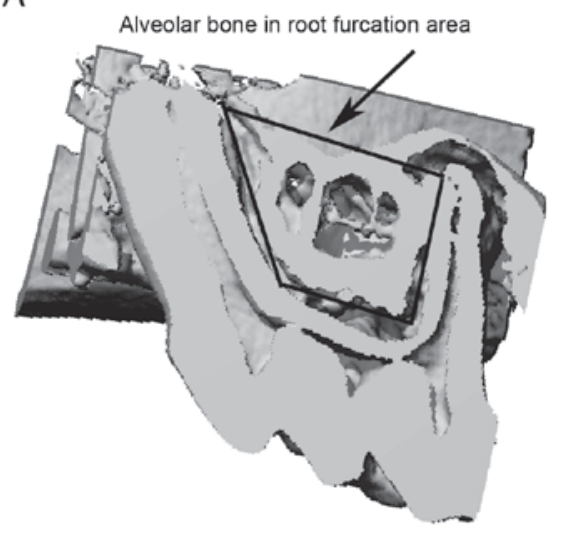

B

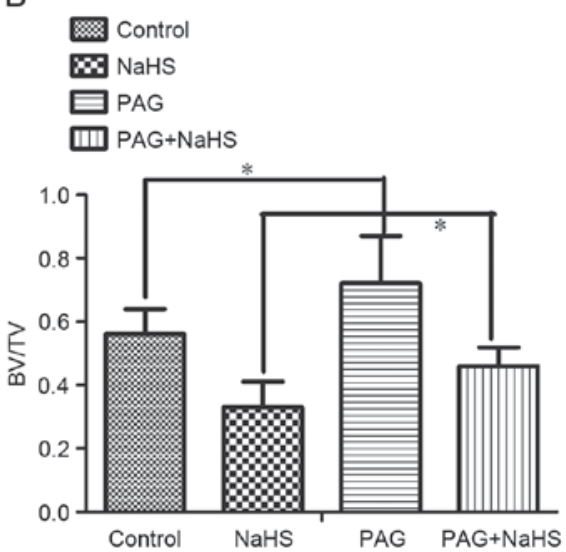

Figure 3. NaHS decreases BMD of alveolar bone in root furcation area. (A) Representative image depicting the region of root furcation and (B) quantification of BMD of alveolar bone in all groups. Data are presented as the mean \pm standard deviation. ${ }^{*} \mathrm{P}<0.05$. OTM, orthodontic tooth movement; NaHS, sodium hydrosulfide; PAG, propargylglycine; BMD, bone mass density; BV/TV, bone volume over total volume.

A

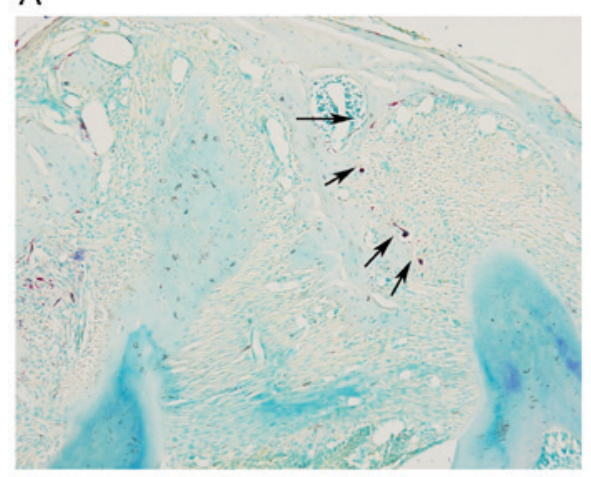

C

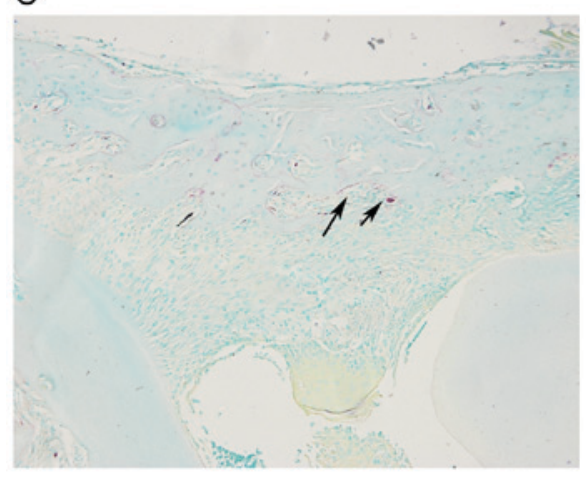

B

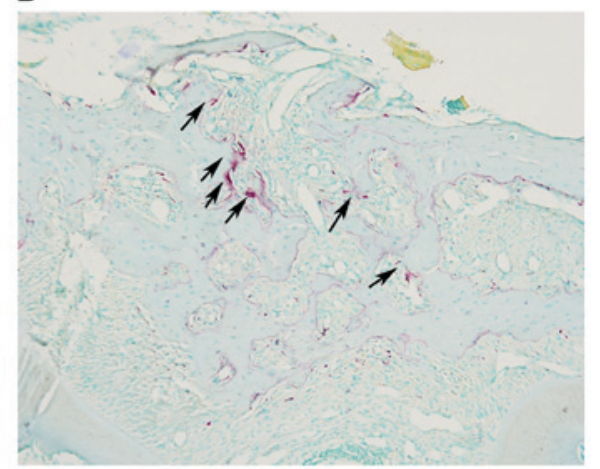

D

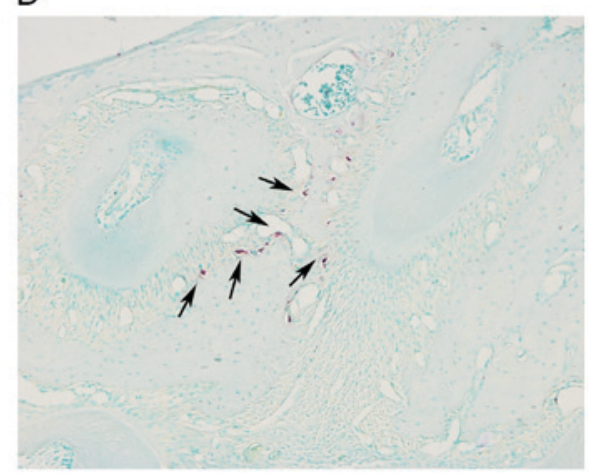

$\mathrm{E}$
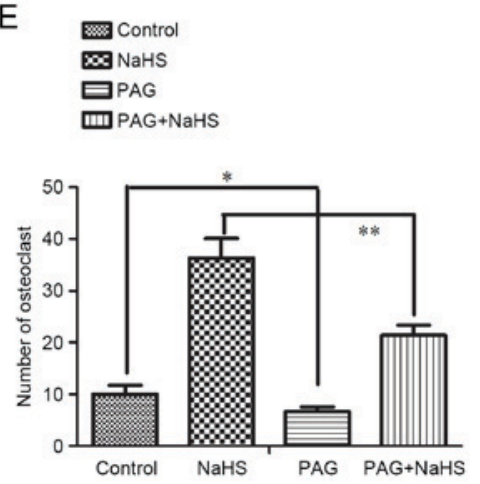

Figure 4. Tartrate-resistant acid phosphatase ${ }^{+}$osteoclasts in alveolar bone between first and second molar in the (A) control, (B) NaHS, (C) PAG and (D) PAG+NaHS groups. Magnification, x100. (E) Quantification of the number of osteoclasts among the groups following each treatment. Arrows indicate the osteoclasts. Data are presented as the mean \pm standard deviation. ${ }^{\mathrm{P}}<0.05 ;{ }^{* *} \mathrm{P}<0.01$. OTM, orthodontic tooth movement; NaHS, sodium hydrosulfide; PAG, propargylglycine. 
A

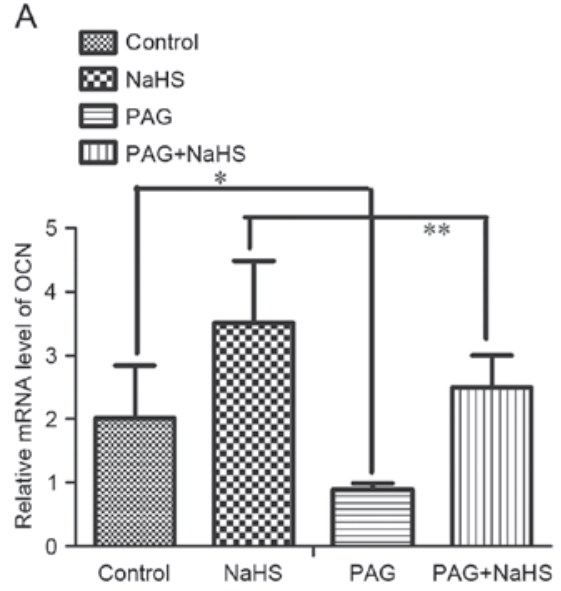

C

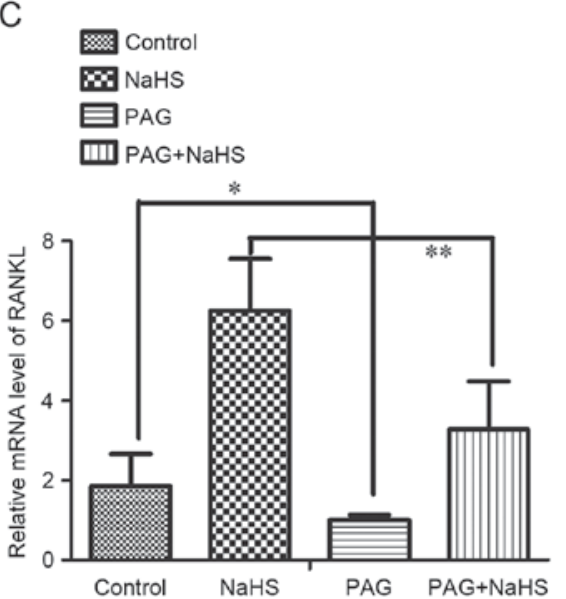

E

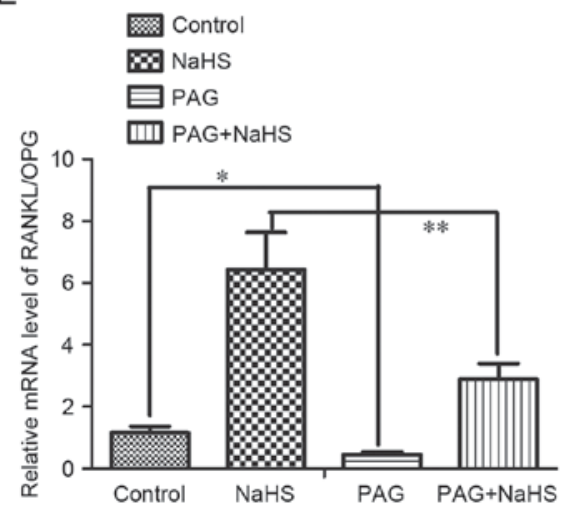

B
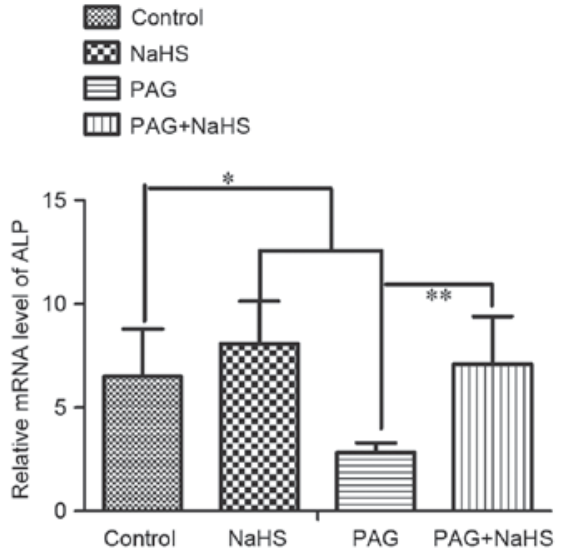

D

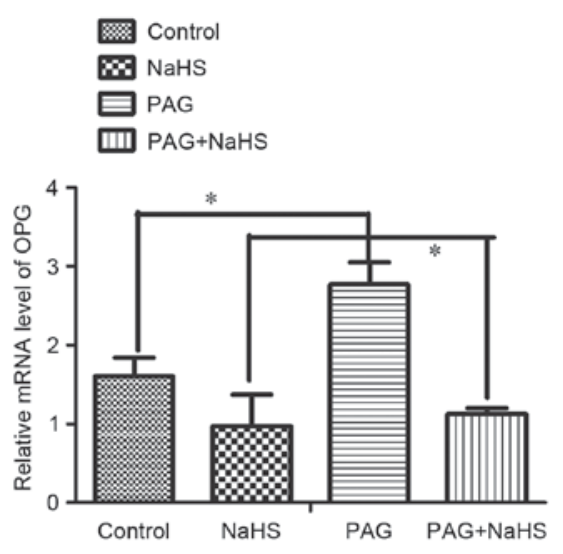

Figure 5. mRNA expression levels of (A) OCN, (B) ALP, (C) RANKL, (D) OPG and (E) ratio of RANKL/OPG in the alveolar bone surrounding the upper first molar region. Data are presented as the mean \pm standard deviation. ${ }^{*} \mathrm{P}<0.05 ;{ }^{* *} \mathrm{P}<0.01$. OTM, orthodontic tooth movement; NaHS, sodium hydrosulfide; PAG, propargylglycine; ALP, alkaline phosphatase; OCN, osteocalcin; OPG, osteoprotegerin; RANKL, tumor necrosis factor ligand superfamily member-11.

no. SAB1306277; OPG, cat. no. SAB4502041, and RANKL, cat. no. SAB4503430; all 1:200, Sigma-Aldrich; Merck KGaA) at $37^{\circ} \mathrm{C}$ for $1 \mathrm{~h}$. Sections were also incubated with second antibody (cat. no. B3640, 1:200, Sigma-Aldrich; Merck KGaA) at $37^{\circ} \mathrm{C}$ for $1 \mathrm{~h}$. Positive staining was visualized with the DAB (D8001, Sigma-Aldrich; Merck KGaA) and counterstained with hematoxylin.

Statistical analysis. Data are expressed as the mean \pm standard deviation. One-way analysis of variance was performed followed by Tukey's test using the SPSS software (version 20.0, IBM Corp., Armonk, NY, USA). $\mathrm{P}<0.05$ was considered to indicate a statistically significant difference.

\section{Results}

Effect of $\mathrm{H}_{2} \mathrm{~S}$ on OTM. When compared with the control animals (Fig. 2A; $127 \pm 15 \mu \mathrm{m}$ ) NaHS resulted in a significant increase in the OTM (Fig. 2B; $341 \pm 14 \mu \mathrm{m}, \mathrm{P}<0.01$ ). There was a significant decrease in the OTM in the PAG-treated 


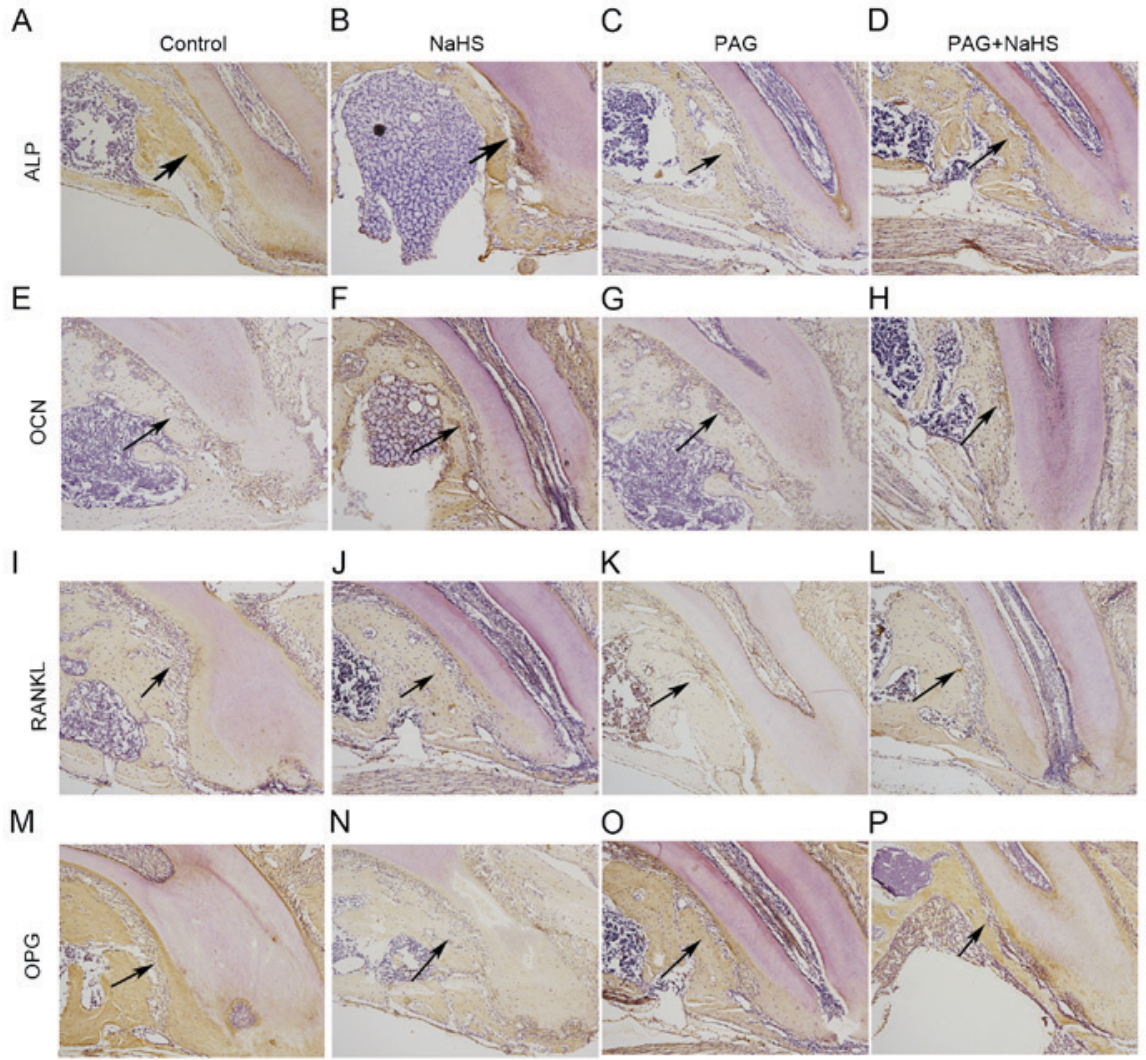

Figure 6. Protein expression levels of ALP in the (A) control, (B) NaHS, (C) PAG and (D) PAG+NaHS groups; of OCN in the (E) control, (F) NaHS, (G) PAG and (H) PAG+NaHS groups; of RANKL in the (I) control, (J) NaHS, (K) PAG and (L) PAG+NaHS groups; of OPG in the (M) control, (N) NaHS, (O) PAG and (P) PAG+NaHS groups. Original magnification, $x 100$. Arrows indicate positive staining. OTM, orthodontic tooth movement; NaHS, sodium hydrosulfide; PAG, propargylglycine; ALP, alkaline phosphatase; OCN, osteocalcin; OPG, osteoprotegerin; RANKL, tumor necrosis factor ligand superfamily member-11.

group (Fig. 2C; $58 \pm 10 \mu \mathrm{m}, \mathrm{P}<0.01$ ) compared with the control. Notably, NaHS rescued the decreased OTM induced by PAG (Fig. 2D; $235 \pm 6 \mu \mathrm{m}, \mathrm{P}<0.01$ and Fig. 2E; $58 \pm 10 \mu \mathrm{m}, \mathrm{P}<0.01$ ).

Effect of $\mathrm{H}_{2} \mathrm{~S}$ on $B M D$. Compared with the control group $(56 \pm 8 \%)$, there was a significant decrease in the BMD measured in the root furcation area in the NaSH group $(33 \pm 7 \%, \mathrm{P}<0.05)$. The PAG group $(72 \pm 15 \%, \mathrm{P}<0.05)$ demonstrated significantly higher BMD than the control group (56 $\pm 8 \%)$. Finally, NaHS $(46 \pm 6 \%, \mathrm{P}<0.05)$ down-regulated the increased BMD-induced by PAG (72 $\pm 15 \%$; Fig. 3$)$.

Effect of $\mathrm{H}_{2} \mathrm{~S}$ on osteoclast numbers. To explore the effect of $\mathrm{H}_{2} \mathrm{~S}$ on bone resorption, the osteoclasts in the alveolar bone between the first and the second molar were identified and quantified with TRAP staining (Fig. 4A-D). Treatment of NaHS (Fig. 3A and B; 36 $\pm 4, \mathrm{P}<0.05$ ) increased the number of osteoclasts whereas PAG $(7 \pm 1, \mathrm{P}<0.05)$ decreased their number, compared with the control group (Fig. 4C and E; $10 \pm 2)$. In addition, the PAG+NaHS group $(21 \pm 2, \mathrm{P}<0.01)$ indicated a significant increase in the number of osteoclasts compared with the PAG group ( $7 \pm 1$; Fig. 4D and E).

Effect of $\mathrm{H}_{2} \mathrm{~S}$ on $\mathrm{mRNA}$ and protein expression levels of OCN, $A L P, R A N K L, O P G$ and $R A N K L / O P G$. To further understand the effect of $\mathrm{H}_{2} \mathrm{~S}$ on bone resorption and bone formation, mRNA and protein expression levels of OCN, ALP, RANKL and OPG in the alveolar bone were investigated. Results demonstrated that both the treatment of NaHS alone and NaHS combined with PAG significantly up-regulated the mRNA expression levels of OCN, ALP and RANKL, whereas it down-regulated the mRNA expression levels of OPG. However, PAG administration decreased significantly the mRNA expression levels of OCN, ALP, and RANKL and increased the mRNA expression levels of OPG (Fig. 5A-D). The mRNA expression ratio of RANKL/OPG was up-regulated by NaHS and down-regulated by PAG (Fig. 5E). Similarly, both the treatment of NaHS alone and NaHS combined with PAG significantly up-regulated the protein expression levels of OCN, ALP and RANKL whereas down-regulated OPG protein expression levels. Additionally, PAG administration decreased significantly the protein expression levels of OCN, ALP and RANKL, and increased OPG protein expression levels (Fig. 6).

\section{Discussion}

Orthodontic treatment usually lasts 24 to 30 months (23). The long treatment duration could increase the risk of caries development, root resorption and periodontal problems (24-26). Accelerating OTM and shortening the time of treatment has become a crucial research area. OTM occurs in the presence of a mechanical stimulus sequenced by remodeling of the alveolar bone and periodontal ligament (1). It was reported that cyclical forces of $60 \mathrm{~Hz}$ could increase the rate of OTM (27). Periodontally accelerated osteogenic orthodontics has also been proved to be a safe technique to accelerate tooth movement 
by reducing the treatment time (28). It is well known that the OTM can be controlled by the size of the applied force and the biological responses from the periodontal ligament, such as the release of inflammatory mediators including cytokines, growth factors, neurotransmitters and arachidonic acid metabolites (2). One of the cytokines, RANKL is considered to be involved in the acceleration of tooth movement by binding to the RANK on osteoclasts stimulating osteoclastogenesis (29). OPG, a circulating glycoprotein, binds to RANKL and inhibits osteoclast activities by competitively inhibiting the RANKLRANK interaction (30). The balance between RANKL and OPG levels determines osteoclast activation, skeletal calcium release and bone remodeling (31).

$\mathrm{H}_{2} \mathrm{~S}$, a gasotransmitter, serves many physiological and pathophysiological roles in maintaining the normal activity of various organs in the neuronal, cardiovascular, gastrointestinal and respiratory systems $(10,11,32,33)$. A previous study indicated that bone marrow mesenchymal stem cells could produce $\mathrm{H}_{2} \mathrm{~S}$, regulating osteogenic differentiation and cell self-renewal, and that $\mathrm{H}_{2} \mathrm{~S}$ deficiency could lead to defects in their differentiation (34). Our previous in vitro study also demonstrated that $\mathrm{H}_{2} \mathrm{~S}$ could promote osteogenic differentiation by up-regulating the expression ratio of OPG/RANKL expression in human PDLSCs (18). It was also demonstrated that $\mathrm{H}_{2} \mathrm{~S}$ significantly increased the expression of ALP, OCN, runt-related transcription factor 2 and collagen 1 in the human PDLSCs with tension force stimulation, and promoted osteogenic differentiation of human PDLSCs by activating the p38-MAPK and ERK signaling pathways $(19,35)$. In the present study, exogenous $\mathrm{H}_{2} \mathrm{~S}$ could up-regulate the expression of ALP and OCN, the ratio of RANKL/OPG and the number of osteoclasts in the alveolar bone. ALP has been commonly studied as an early marker of osteogenic differentiation in tension force experiments and $\mathrm{OCN}$ is a key transcription factor in the modulation of osteogenic differentiation and bone formation (19). The results of the present study revealed that $\mathrm{H}_{2} \mathrm{~S}$ could up-regulate the process of osteogenesis, osteoclastic activities and bone remodeling. These findings are consistent with our previous study, where mechanical stimulation and $\mathrm{H}_{2} \mathrm{~S}$ could enhance the osteogenic differentiation $(18,19,35)$. These results were also in accordance with some studies illustrating that $\mathrm{H}_{2} \mathrm{~S}$ could enhance RANKL-induced osteoclast differentiation in vitro and induce osteoclast differentiation in vivo $(17,36)$.

It is generally known that remodeling and modeling of alveolar bone is considered as the most important aspect in orthodontic tooth movement $(37,38)$. In the present study, non-invasive micro-CT was used to monitor the migration of tooth and the internal conditions of the alveolar bone, such as bone density, during orthodontic and $\mathrm{H}_{2} \mathrm{~S}$ treatment. Data of the present study indicated that systemic administration of NaHS accelerated the OTM and reduced the alveolar bone density, providing evidence supporting that $\mathrm{H}_{2} \mathrm{~S}$ could promote osteogenesis and osteoclastogenesis differentiation, and might facilitate the tooth movement during orthodontic treatment. In addition, it was observed that PAG decreased the OTM in the mouse model. This change might be associated with a reduction of endogenous $\mathrm{H}_{2} \mathrm{~S}$.

It is worth noting that the present study was based on an OTM mouse model, and is different from clinical work.
The mechanism of how $\mathrm{H}_{2} \mathrm{~S}$ regulates OTM is still unclear. However, the present study may provide a novel understanding on how to accelerate the tooth movement and shorten the treatment time.

In conclusion, the present study provided an in vivo evidence that $\mathrm{H}_{2} \mathrm{~S}$ increased the rate of tooth movement by promoting osteogenesis and osteoclastogenesis differentiation in alveolar bone. These findings could encourage further studies looking for a potential therapeutic value of $\mathrm{H}_{2} \mathrm{~S}$ for accelerating the orthodontic treatment.

\section{Acknowledgements}

This study was supported by the National Science Foundation of China (grant no. 81371177) and the Shanghai Science and Technology Committee (grant no. 17140903700).

\section{References}

1. Melsen B: Biological reaction of alveolar bone to orthodontic tooth movement. Angle Orthod 69: 151-158, 1999.

2. Krishnan V and Davidovitch Z: Cellular, molecular, and tissuelevel reactions to orthodontic force. Am J Orthod Dentofacial Orthop 129: 469.e1-32, 2006.

3. Masella RS and Meister M: Current concepts in the biology of orthodontic tooth movement. Am J Orthod Dentofacial Orthop 129: 458-468, 2006.

4. Zahrowski JJ: Optimizing orthodontic treatment in patients taking bisphosphonates for osteoporosis. Am Orthod Dentofacial Orthop 135: 361-374, 2009.

5. Pichler K, Loreto C, Leonardi R, Reuber T, Weinberg AM and Musumeci G: RANKL is downregulated in bone cells by physical activity (treadmill and vibration stimulation training) in rat with glucocorticoid-induced osteoporosis. Histol Histopathol 28: 1185-1196, 2013.

6. Leonardi R, Loreto C, Talic N, Caltabiano R and Musumeci G: Immunolocalization of lubricin in the rat periodontal ligament during experimental tooth movement. Acta Histochem 114: 700-704, 2012.

7. Cardile V, Musumeci G, Sicurezza E, Caggia S, Rusu MC, Leonardi R and Loreto C: Expression of TRAIL and its receptors DR5 and DcR2 in orthodontic tooth movement. Histol Histopathol 28: 933-940, 2013.

8. Kabil O, Motl N and Banerjee R: H2S and its role in redox signaling. Biochim Biophys Acta 1844: 1355-1366, 2014.

9. Shibuya N, Tanaka M, Yoshida M, Ogasawara Y, Togawa T, Ishii K and Kimura H: 3-Mercaptopyruvate sulfurtransferase produces hydrogen sulfide and bound sulfane sulfur in the brain. Antioxid Redox Signal 11: 703-714, 2009.

10. Yang G, Wu L, Jiang B, Yang W, Qi J, Cao K, Meng Q, Mustafa AK, Mu W, Zhang S, et al: $\mathrm{H} 2 \mathrm{~S}$ as a physiologic vasorelaxant: Hypertension in mice with deletion of cystathionine gamma-lyase. Science 322: 587-590, 2008.

11. Abe $\mathrm{K}$ and Kimura $\mathrm{H}$ : The possible role of hydrogen sulfide as an endogenous neuromodulator. J Neurosci 16: 1066-1071, 1996.

12. Papapetropoulos A, Pyriochou A, Altaany Z, Yang G, Marazioti A, Zhou Z, Jeschke MG, Branski LK, Herndon DN, Wang R and Szabó C: Hydrogen sulfide is an endogenous stimulator of angiogenesis. Proc Natl Acad Sci USA 106: 21972-21977, 2009.

13. Li L, Bhatia M, Zhu YZ, Zhu YC, Ramnath RD, Wang ZJ, Anuar FB, Whiteman M, Salto-Tellez M and Moore PK: Hydrogen sulfide is a novel mediator of lipopolysaccharideinduced inflammation in the mouse. FASEB J 19: 1196-1198, 2005.

14. Olson KR, Healy MJ, Qin Z, Skovgaard N, Vulesevic B, Duff DW, Whitfield NL, Yang G, Wang R and Perry SF: Hydrogen sulfide as an oxygen sensor in trout gill chemoreceptors. Am J Physiol Regul Integr Comp Physiol 295: R669-R680, 2008.

15. Irie K, Ekuni D, Tomofuji T, Endo Y, Kasuyama K, Yaegaki K and Morita M: Combined effects of hydrogen sulfide and lipopolysaccharide on osteoclast differentiation in rats. J Periodontol 83: $522-527,2012$. 
16. Irie K, Ekuni D, Yamamoto T, Morita M, Yaegaki K, Ii H and Imai T: A single application of hydrogen sulphide induces a transient osteoclast differentiation with RANKL expression in the rat model. Arch Oral Biol 54: 723-729, 2009.

17. Su Y, Liu D, Liu Y, Zhang C, Wang J and Wang S: Physiologic levels of endogenous hydrogen sulfide maintain the proliferation and differentiation capacity of periodontal ligament stem cells. J Periodontol 86: 1276-1286, 2015.

18. Liao C and Hua Y: Effect of hydrogen sulphide on the expression of osteoprotegerin and receptor activator of NF- $x \mathrm{~B}$ ligand in human periodontal ligament cells induced by tension-force stimulation. Arch Oral Biol 58: 1784-1790, 2013.

19. Jiang $Z$ and Hua Y: Hydrogen sulfide promotes osteogenic differentiation of human periodontal ligament cells via p38-MAPK signaling pathway under proper tension stimulation. Arch Oral Biol 72: 8-13, 2016.

20. Cao H, Kou X, Yang R, Liu D, Wang X, Song Y, Feng L, He D, Gan Y and Zhou Y: Force-induced Adrb2 in periodontal ligament cells promotes tooth movement. J Dent Res 93: 1163-1169, 2014.

21. Yan Y, Liu F, Kou X, Liu D, Yang R, Wang X, Song Y, He D, Gan Y and Zhou Y: T cells are required for orthodontic tooth movement. J Dent Res 94: 1463-1470, 2015.

22. Schmittgen TD and Livak KJ: Analyzing real-time PCR data by the comparative C(T) method. Nat Protoc 3: 1101-1108, 2008.

23. Long H, Pyakurel U, Wang Y, Liao L, Zhou Y and Lai W: Interventions for accelerating orthodontic tooth movement: A systematic review. Angle Orthod 83: 164-171, 2013.

24. Nimeri G, Kau CH, Abou-Kheir NS and Corona R: Acceleration of tooth movement during orthodontic treatment-a frontier in orthodontics. Prog Orthod 14: 42, 2013.

25. Kau CH, Kantarci A, Shaughnessy T, Vachiramon A, Santiwong P, de la Fuente A, Skrenes D, Ma D and Brawn P: Photobiomodulation accelerates orthodontic alignment in the early phase of treatment. Prog Orthod 14: 30, 2013.

26. Kau CH: A radiographic analysis of tooth morphology following the use of a novel cyclical force device in orthodontics. Head Face Med 7: 14, 2011

27. Nishimura M, Chiba M, Ohashi T, Sato M, Shimizu Y, Igarashi $\mathrm{K}$ and Mitani $\mathrm{H}$ : Periodontal tissue activation by vibration: Intermittent stimulation by resonance vibration accelerates experimental tooth movement in rats. Am J Orthod Dentofacial Orthop 133: 572-583, 2008
28. Wilcko WM, Wilcko T, Bouquot JE and Ferguson DJ: Rapid orthodontics with alveolar reshaping: Two case reports of decrowding. Int J Periodontics Restorative Dent 21: 9-19, 2001.

29. Ciacli C and Puşchiţă M: RANKL/RANK/OPG molecular complex-control factors in bone remodeling in psoriatic arthritis. Rev Med Chir Soc Med Nat Iasi 115: 354-360, 2011.

30. Simonet WS, Lacey DL, Dunstan CR, Kelley M, Chang MS, Lüthy R, Nguyen HQ, Wooden S, Bennett L, Boone T, et al: Osteoprotegerin: A novel secreted protein involved in the regulation of bone density. Cell 89: 309-319, 1997.

31. Karsenty G: The genetic transformation of bone biology. Genes Dev 13: 3037-3051, 1999.

32. Souza LK, Araújo TS, Sousa NA, Sousa FB, Nogueira KM, Nicolau LA and Medeiros JV: Evidence that d-cysteine protects mice from gastric damage via hydrogen sulfide produced by d-amino acid oxidase. Nitric Oxide 64: 1-6, 2017.

33. Ivanciuc T, Sbrana E, Ansar M, Bazhanov N, Szabo C, Casola A and Garofalo RP: Hydrogen sulfide is an antiviral and antiinflammatory endogenous gasotransmitter in the airways. Role in respiratory syncytial virus infection. Am J Respir Cell Mol Biol 55: 684-696, 2016.

34. Liu Y, Yang R, Liu X, Zhou Y, Qu C, Kikuiri T, Wang S, Zandi E, Du J, Ambudkar IS and Shi S: Hydrogen sulfide maintains mesenchymal stem cell function and bone homeostasis via regulation of $\mathrm{Ca}(2+)$ channel sulfhydration. Cell Stem Cell 15: 66-78, 2014.

35. Qin J and Hua Y: Effects of hydrogen sulfide on the expression of alkaline phosphatase, osteocalcin and collagen type I in human periodontal ligament cells induced by tension force stimulation. Mol Med Rep 14: 3871-3877, 2016.

36. Itou T, Maldonado N, Yamada I, Goettsch C, Matsumoto J, Aikawa M, Singh S and Aikawa E: Cystathionine $\gamma$-lyase accelerates osteoclast differentiation: Identification of a novel regulator of osteoclastogenesis by proteomic analysis. Arterioscler Thromb Vasc Biol 34: 626-634, 2014.

37. Viecilli RF, Katona TR, Chen J, Hartsfield JK Jr and Roberts WE: Orthodontic mechanotransduction and the role of the P2X7 receptor. Am J Orthod Dentofacial Orthop 135: 694.e1-16; discussion 694-695, 2009.

38. Krishnan V and Davidovitch Z: On a path to unfolding the biological mechanisms of orthodontic tooth movement. J Dent Res 88: 597-608, 2009. 